\title{
Comparison of active management of labour versus traditional approach
}

\author{
Snehlata ${ }^{1}$, Kumar A. ${ }^{2}$, Sawant V. ${ }^{3}$ \\ ${ }^{1}$ Dr. Snehlata, Department of Obstetrics \& Gynaecology, ${ }^{2}$ Dr. Abhishek Kumar, Department of General Surgery; ${ }^{1,2}$ Sadar \\ Hospital, Hazaribagh \& Visiting Consultant at Vandana Nursing Home, Shivpuri, Hazaribag, Jharkhand, India, \\ ${ }^{3}$ Dr. Vasudha Sawant, Associate Professor, Department of Obstetrics \& Gynaecology, Dr. D.Y. Patil Hospital, \\ Kadamwadi, Kolhapur, India.
}

Corresponding Author: Dr. Snehlata, Department of Obstetrics \& Gynaecology, Sadar Hospital, Hazaribagh \& Visiting Consultant at Vandana Nursing Home, Shivpuri, Hazaribag, Jharkhand, India, E-mail:sneha91@ymail.com

\begin{abstract}
Background: Management of spontaneous labour is an important issue. Dystocia accounts for increased rate of LSCS. Prolonged labours are associated with higher maternal and neonatal morbidity. With active management, these complications could be reduced. Aims: To study outcome of labour, maternal \& perinatal morbidity and mortality with active management of labour. Methods: 100 primigravidas, at term were randomly assigned to 2 groups-study groupactive management $(\mathrm{N}=50)$ and control group $(\mathrm{n}=50)$. Women in active group were managed by early amniotomy and augmentation with Oxytocin at $6 \mathrm{mIU} / \mathrm{ml}$. In the control group, women received conservative care, amniotomy after $6 \mathrm{~cm}$ dilatation and oxytocin at $1 \mathrm{mIU} / \mathrm{ml}$. In both groups labour was monitored using modified WHO partogram. Caesarean was done for standard obstetric indications. Results: In active management caesarean rate was 12 percent, as compared with 18 percent in control. Mean length of labour in study group was $5.6 \mathrm{hrs}$ as compared to 7.1 in control group. The 6 percent reduction in the caesarean section rate was primarily due to a decrease in incidence of dystocia. With active management, the average length of labour was shortened by 1.5 hours, because of early amniotomy and oxytocin. No statistical difference was seen in both groups as regards to mortality and morbidity. Conclusions: Active management of labour reduces the incidence of dystocia, decreases duration of labour and increases the rate of vaginal delivery without increasing maternal or neonatal morbidity.
\end{abstract}

Keywords: Primigravida, Active management, Partogram, spontaneous labour

\section{Introduction}

Management of spontaneous labour has become an important issue both in the developing and developed world. Approximately half a million women lose their lives every year because of the complications of pregnancy and $99 \%$ of these occur in developing countries [1]. The safe motherhood initiative (SMI) emphasizes that the monitoring of labour for early detection of Dystocia is one of the most important approaches for reducing maternal and neonatal mortality and morbidity [2,3]. In this context, the partogram has been adopted by the World Health Organization (WHO) to monitor labour in maternity clinics in developing countries as a simple managerial tool to prevent prolonged labour and its sequelae. Freidman, 1954 has 1st devised Partogram.

Manuscript received: $16^{\text {th }}$ November 2019

Reviewed: $26^{\text {th }}$ November 2019

Author Corrected: $4^{\text {th }}$ December 2019

Accepted for Publication: $7^{\text {th }}$ December 2019
Active management of labour is an approach to labour diagnosis and management in nulliparous woman. Two of its components are Amniotomy \& Oxytocin have been widely used [4,5]. On the basis of this, active management of labour, first introduced by O' Driscoll et al in the year 1968, at the national maternity hospital in Dublin, Ireland, and it was devised to ensure short labours in nulliparous women. In addition, active management of labour was noted to be associated with a lower caesarean section rate [6-15].

\section{Methods}

Duration: Two years.

Type of study: Comparative study.

Sample size: Fifty samples in each group.

Data analysis: Data was accumulated in Microsoft excel and was analysed statistically. 


\section{Original Research Article}

Ethical consideration: Ethical approval department was taken.

This study was conducted from August 2008 to August 2010 in Department of Obstetrics \& Gynaecology, Padmashree Dr. D Y Patil Hospital, Kadamwadi, Kolhapur under D Y Patil University, Kolhapur. Primigravidas attending the labour room with full term live pregnancy with vertex presentation in active phase of labour without any obvious risk factors and were thought to be suitable for vaginal delivery, on vaginal examination were considered for this study.

\section{Inclusion Criteria}

- Primigravida

- Term pregnancy (37 weeks completed)

- Singleton Pregnancy

- Cephalic Presentation

\section{Exclusion Criteria}

- Multiple Pregnancy

- Congenital Anomaly

- Malpresentation

- APH

- Preterm Pregnancy.

- $\mathrm{CPD}$

100 patients admitted with the labor pains will be selected at random for this study according to inclusion and exclusion criteria. Criteria for labor, painful uterine contraction with progressive dilatation and effacement of the cervix. They will be examined at the time of admission first. Cervical dilatation at admission will be charted at 'zero' time on partogram.

The active management protocol consists of a strict diagnosis of labor based on regular palpable uterine contractions and a cervical effacement of at least $80 \%$.

Amniotomy will be performed at $3 \mathrm{~cm}$ dilatation of cervix, and a regimen of high-dose oxytocin will be started with $6 \mathrm{mU} / \mathrm{min}$ and increased $6 \mathrm{mU} / \mathrm{min}$ every 15 minutes (to a maximum of $36 \mathrm{mU}$ per minute) until seven contractions in 15 minutes or adequate labor progress was obtained. Dilatation of $1 \mathrm{~cm}$ per hour during the first stage of labor and $1 \mathrm{~cm}$ of descent per hour during the second stage of labor defined adequate progress.

The control protocol consists of admission to the hospital for labor and delivery with a cervical dilatation and effacement of cervix in the presence of regular uterine contractions.

Amniotomy will be performed at the attending physician's discretion. A regimen of low-dose Oxytocin will begin at $1 \mathrm{mU} / \mathrm{min}$ and increased by $1 \mathrm{mU} / \mathrm{min}$ every 30 minutes until adequate labor was achieved.

All parameters for fetal morbidity, mortality and maternal morbidity will be evaluated and compared in the two groups. Further progress of labor evaluation, mode of delivery and related complication if any will also be studied.

\section{Results}

Age incidence- The groups had range of age between 18 years to 26 years in study group and 19 years to 30 years in control group. A further age description of the groups is described below (Table 1).

Table 1: Distribution through age incidence.

\begin{tabular}{|c|c|c|c|c|}
\hline Age & Study group & \%age & Control Group & \%age \\
\hline $15-20$ & 22 & 44 & 23 & 46 \\
\hline $21-25$ & 23 & 46 & 25 & 50 \\
\hline $26-30$ & 5 & 10 & 2 & 4 \\
\hline$>30$ & & & & \\
\hline
\end{tabular}

Majority of patients were in the age group of 18-25 years in both groups (90\% Vs 96\%) Age distribution was comparable in both groups. There was no significant difference in age between the two groups.

Status of labor at admission and labor: At hospital admission, the percentage of women whose membranes had ruptured was similar in the two study groups (active management, 18\%; usual care, 14\%), as was the mean cervical dilatation at first examination (study group, $3.22 \mathrm{~cm}$, control group, $3.52 \mathrm{~cm}$ ) (Table 2). 
Original Research Article

Table 2: Status of labor at admission and labor.

\begin{tabular}{|l|c|c|}
\hline & Study group & Control group \\
\hline Mean cervical dilatation at admission(cm) & 3.22 & 3.52 \\
\hline Artificial rupture of membranes (\%) & 82 & 66 \\
\hline Mean time from admission to rupture (min) & 38 & 175 \\
\hline Mean dilation at rupture (cm) & 3.22 & 6.06 \\
\hline
\end{tabular}

Practices for the management of labor mandated by the protocol differed in the two groups. Women in the study group had more frequent vaginal examinations (mean frequency, every 1.6 hours, as compared with every 2.5 hours in the usualcare group). Their membranes were artificially ruptured more often (82\% vs. 66\%) and earlier (within one hour of admission in 82 percent, as compared with 14 percent in the control group).

Table 3: Comparison of oxytocin used in labour

\begin{tabular}{|l|c|c|}
\hline & Study group & Control group \\
\hline Induction of labour with oxytocin (\%) & $100 \%$ & $66 \%$ \\
\hline Mean initial dose (mU/min) & 6 & 1 \\
\hline Mean maximal dose (mU/min) & 22.8 & 6.62 \\
\hline
\end{tabular}

All women in the study group received oxytocin (100 percent vs. 66 percent), and the time from admission to the administration of oxytocin was typically 2 hours shorter (1.7 vs. 4.0 hours). The mean maximal dose of oxytocin administered was higher in the study group (22.8 mU per minute vs. $6.62 \mathrm{mU}$ per minute in the control group) (Table 3).

Table 4: Comparison of method of delivery

\begin{tabular}{|l|c|c|c|c|}
\hline \multicolumn{1}{|c|}{ Method of Delivery } & Study group & \% & Control group & \% \\
\hline VD & $40 / 50$ & 80 & $37 / 50$ & 74 \\
\hline IVD & $4 / 50$ & 8 & $4 / 50$ & 18 \\
\hline LSCS Stage 1 & $5 / 50$ & 10 & $9 / 50$ & 0 \\
\hline LSCS Stage 2 & $1 / 50$ & 2 & $0 / 50$ & 8 \\
\hline
\end{tabular}

There was a small but consistent decrease in the rate of caesarean section during first stage and second stage labor, as well as in the rate of operative vaginal delivery in the study group (Table 4). None of these differences were statistically significant. For both groups, the rate of caesarean section performed because of fetal distress was low (study group, 6\%, control group, 10\%). Therefore, the overall caesarean sections performed because labor failed to progress (Table 5).

Table 5: Distribution of the patient by indication of caesarean section

\begin{tabular}{|l|c|c|c|c|}
\hline & Study Group & \% & Control Group & $\%$ \\
\hline Secondary arrest of cervical dilatation & $2 / 50$ & 4 & $4 / 9$ & 8 \\
\hline Secondary arrest of descent & $1 / 50$ & 2 & $0 / 0$ & 0 \\
\hline Fetal distress & $3 / 50$ & 6 & $5 / 9$ & 10 \\
\hline
\end{tabular}

100 nulliparous women eligible for the study agreed to participate and were randomly assigned to the study group ( $\mathrm{n}=$ $50)$ or to the control group $(n=50)$. The characteristics of the women in the two groups were balanced with regard to race, age, education. Among the 100 women, the rate of caesarean section was different in both groups: $12 \%$ in the active-management group and $18 \%$ in the usual-care group. In both groups, caesarean sections were performed at a similar rate in response to the failure of labor to progress (study group, 6\%; control group, $8 \%$ ). 
Original Research Article

Table 6: Comparison of mean duration of labor

\begin{tabular}{|l|c|c|c|}
\hline & Mean $\mathbf{1}^{\text {st }}$ stage hrs. & Mean 2 $^{\text {nd }}$ stage min. & ${\text { Mean } \mathbf{3}^{\text {rd }} \text { stage min. }}$ \\
\hline Study group & 5.6 & 42.7 & 7.66 \\
\hline Control group & 7.1 & 49.9 & 8.62 \\
\hline
\end{tabular}

The mean length of labour was 5.6 hours in the study group and 7.1 hours in the control group. A difference in the length of labor remained when the groups were stratified according to the extent of cervical dilatation at first examination. The difference in the length of labour is (6.3 vs 7.9) 1.5 hours (Table 6).

\section{Table 7: Comparison of duration of labour in both group}

There was a comparable rate between the two groups when results of duration of labour are considered. In study group; there was 1 patient who had duration of labour $>12 \mathrm{hrs}$ and in control group; there were 3 patients (Table 7).

\begin{tabular}{|c|c|c|}
\hline & Labour $>\mathbf{1 2} \mathbf{~ h r s}$ & $\mathbf{\%}$ \\
\hline Study group & $1 / 50$ & 2 \\
\hline Control group & $3 / 50$ & 6 \\
\hline
\end{tabular}

This indicates prolong labour was less in active management of labour i.e. $2 \%$ and in control group $6 \%$ (Table 8 ).

Table 8: Comparison of postnatal maternal complication

\begin{tabular}{|l|c|c|c|c|}
\hline & Study Group & $\mathbf{\%}$ & Control Group & \% \\
\hline BT & $0 / 0$ & 0 & $1 / 50$ & 2 \\
\hline PPH & $1 / 50$ & 2 & $1 / 50$ & 2 \\
\hline Maternal Fever & $0 / 50$ & 0 & $3 / 50$ & 6 \\
\hline
\end{tabular}

The incidence of maternal morbidity was very low in the current study at about $2 \%$. Both the groups did not vary much regarding the incidence of vaginal lacerations, extension of episiotomy \& cervical tears. Blood transfusion was required post-natally for 1 patient in the control group. She was an anaemic patient with $\mathrm{Hb} \%$ of $7.4 \mathrm{~g} \%$. Postpartum Haemorrhage (PPH) which was defined as a blood loss of more than $500 \mathrm{ml}$ was seen in a total of 1 patient each in both the group. Maternal fever is more (6\%) in control group because of prolong labour.

Table 9: Comparison of neonatal outcome

\begin{tabular}{|l|c|c|c|}
\hline Parameter studied & Study group & Control group & P value \\
\hline Lethargy & 0 & 2 & $>0.05 \mathrm{NS}$ \\
\hline R. T. Feed & 1 & 3 & $>0.05 \mathrm{NS}$ \\
\hline Need for oxygen & 3 & 2 & $>0.05 \mathrm{NS}$ \\
\hline Meconium air way & 0 & 0 & $<0.01$ \\
\hline Mechanical Ventilation & 0 & 12 & $<0.01$ \\
\hline NICU days & 3 & 6 & $>0.05$ \\
\hline Bag. Mask Resuscitation & 3 & 1 & $>0.05 \mathrm{NS}$ \\
\hline Intubation & 0 & & $>0.05 \mathrm{NS}$ \\
\hline
\end{tabular}

NS: Not significant $\mathrm{p}$ value.

Among the infants, it was observed that no significant differences between the two groups in the frequency of lethargy, jaundice, seizures, R. T. Feed, resuscitation at birth. Admission to the neonatal intensive care unit in control group $(\mathrm{p}<0.05)$ observed that difference in mean or proportion was statistically significant at $5 \%$ L.S. Only one infant in control group required intubation and one had five-minute Apgar scores of 6 (Table 9). 


\section{Discussion}

O'Driscoll and colleagues at the National Maternity Hospitalin Dublin, Ireland, pioneered a multifaceted approach to the management of labour in nulliparous women that is now referred to as active management of labor [15]. It was introduced to shorten labour at a time when the rate of caesarean section was under 5 percent.

Active management of labour includes strict criteria for the diagnosis of labour, early rupture of the amniotic membranes, prompt intervention with high-dose oxytocin in the event of inefficient uterine action, and a commitment never to leave a woman unattended during labour. The persistently low rate of caesarean delivery at the National Maternity Hospital led other obstetrical services to use active management of labour as a means to reduce rates of caesarean section. However, the efficacy and safety of this protocol were not universally accepted [16].

Artificial rupture of the amniotic membranes (amniotomy) with the intention of accelerating the progress of labour is among the most commonly performed procedures in obstetrics. Early amniotomy has been advocated to prevent dystocia in women in spontaneous labor $[17,18]$. In the first stage of labour, dystocia is defined as a delay in progress beyond which medical intervention, usually the administration of oxytocin, is considered justified.

In women with dystocia, oxytocin is used to stimulate labour and to distinguish functional uterine disorders from cephalopelvic disproportion. The failure of dystocia to respond to medical treatment may lead to caesarean section; among nulliparous women,dystocia is the most frequent indication for caesarean section.

The results of some previous randomized trials $[19,20,21,22]$ but not all [23] suggested that early amniotomy reduces the average duration of labour. Whether a policy of early amniotomy reduces the frequency of dystocia, however, is not known. In addition, earlier studies did not have adequate power to determine whether the rate of oxytocin administration or the rate of caesarean section was affected by early amniotomy.

In the present study, randomized nulliparous women at completed 37 weeks of gestation was classified into two groups: In study group (Active management) \& control group (Traditional approach) and maternal and fetal outcomes were compared between these two groups.
The preent study was undertaken to determine whether early amniotomy \& acceleration of labour with oxytocin for nulliparous women in spontaneous labour was associated with a reduction in the risk of dystocia \& lowering the rate of caesarean section, including shorten the duration of labour.

Secondary outcomes included the abnormalities in the fetal heart rate, and indicators of maternal and neonatal morbidity.

A comparison between the present study and similar studies is presented in the below section. Indeed, any analysis of Active management of labour for lowering the rate of caesarean section is difficult. One of the main things is the variation in the management i.e. timing of the ARM, administration of oxytocin, \& CPD. Separate analysis of active management of labour and traditional approach is justified.

In this clinical trial, the present study investigated whether the implementation of a protocol for active management of labor would safely lower the rate of caesarean section among nulliparous women. The present study included all the components of the National Maternity Hospital protocol for active management of labor: customized education, specific criteria for the diagnosis of labor, specific management steps, use of high-dose oxytocin, and one-to-one nursing [15]. Active management was implemented by a separate staff to guard against the bias that could result if the same staff simultaneously cared for patients in labor under both the active-management and usualcare protocols.

The safety of the protocol, including the use of highdose oxytocin and management of labor by midwives, was confirmed. Shorter labor and a decreased occurrence of maternal fever were also noted. However, the anticipated substantial decrease in the rate of caesarean section was observed. The overall rate of caesarean section was decreased in study group. The rate of first-stage caesarean section was slightly lower in the study group. This decrease was statistically significant\& clinically relevant, \& the overall rate of caesarean section was also altered.

In another large, randomized trial of active management of labor, the rate of caesarean section was reduced from 14.1 percent to 10.5 percent, and the difference reached statistical significance only after a number of factors 
Original Research Article

were controlled for. The fact that in that trial the labor of women in both study groups was managed in the same labor and delivery unit by the same personnel could have introduced bias that accounted for differences of the order of magnitude of the observed results.

The slightly higher rate of caesarean section in the control group in the study of López-Zeno et al [11]. (14\%) could be due to the fact that women with medical conditions such as hypertension and diabetes were not excluded from their study.

A striking difference between the data on caesarean sections from the randomized trials of active management of labor and those from the National Maternity Hospital is the distribution of caesarean sections between the first and second stages of labor [15]. The rates of first-stage caesarean section were similar in all four cases: 10 percent in this study, 5.2\% in Frigoletto et al [24], 7\% in the trial of López-Zeno et al. [11], and $4.8 \%$ at the National Maternity Hospital [15]. In contrast, active management of labor resulted in markedly different rates of caesarean section during the second stage of labor: $2 \%$ in the present study, $4 \%$ in Frigoletto et al [24], 3\% in the trialof López-Zeno et al. [11], as compared with only $0.2 \%$ at the National Maternity Hospital [15].

\section{Conclusion}

Active management of labor reduces the incidence of dystocia and increases the rate of vaginal delivery, reduce the rate of caesarean section in nulliparous women and was associated with a somewhat shorter duration of labour without increasing maternal or neonatal morbidity. The effective ingredient seems to be the presence of a companion in labour with the performance of amniotomy or administration of oxytocin.

\section{What the study adds to the existing knowledge?}

In this randomized trial, it was observed that the activemanagement protocol was effective in reducing the rate of caesarean section. On the basis of results of the previously reported randomized trial and observational data, some managed-care organizations are suggesting that active management be instituted as the standard of practice in order to reduce the rate of caesarean sections. Although the active-management protocol did have some benefits - such as shorter labor and a decreased occurrence of maternal fever.

\section{Author's contribution}

Dr. Snehlata: Concept, study design

Dr. Abhishek Kumar: Manuscript preparation

Dr. Vasudha Sawant: Statistical analysis

Funding: No funding sources

Conflict of interest: None declared

Ethical Approval: This study was approved by the Institutional Ethics Committee

\section{References}

1. Fathalla $M$, Former president of international Federation of Obstetricians and Gynecologists, Assiyut university Egypt, Misoprostol in obstetrics and Gynecology-A plea letter not to take the drug off the market. 2006.

2. The partographa 1988 Section I, II, III and IV WHO/ $\mathrm{MCH} / 88$ publication of the world health Organisation Maternal and child health unit, Division of Family Health, Geneva. Available at http://apps.who.int /iris/ bitstream/10665/58589/1/WHO_FHE_MSM_94.4.pdf.

3. Mahler H. The safe motherhood Initiative: A call to Action. Lancet. 1987;1(8534):668-670. doi: https://doi. org/ 10.1016/S0140-6736(87)90423-5.

4. Philpott RH. Graphic Record in labour. British Med J. 1972;4(5833):163-165. doi: 10.1136/bmj.4.5833.163.

5. F. Gary Cunningham, Kenneth J.Leveno, Stevenl. Bljohn C. Hauth, Larry C. Gilstrap Iii, Katharine D. Wenstrom; WILLIAMS obstetrics, twenty-second edition, Mc GRAW-HILL, Medical publishing Division. Pg 439, Chap 17 Normal labour and delivery.

6. O'driscoll K., Jackson R.J.A. Gallagher JT. Prevention of prolonged labour. Brit Med J. 1969;2 (5655) : 477-480. doi: 10.1136/bmj.2.5655.477.

7. DC. Dutta; Textbook of Obstetrics including Perinatology and contraception, VI edition, New central publications. Chap 12 and chap 34, Normal labour\& Active management of labour, pp 131,527-529.

8. World Health Organization. Having a Baby in Europe. Public Health in Europe No. 26, Copenhagen: Regional Office for Europe, 1985a.

9. Kitzinger, S. (1992) Ourselves as mothers: the universal experience of motherhood Toronto: Bantam Books. In: Young, J. (1995) The medicalisation of childbirth : a cause for concern. Midwifery 3 (1) Spring. 9-16 


\section{Original Research Article}

10. Keirse M. Preparing the cervix for induction of labour. In: Chalmers I, Enkin M, Keirse M (eds). Effective Care in Pregnancy and Childbirth. Oxford: Oxford University Press, 1989.

11. López-Zeno JA, Peaceman AM, Adashek JA, Socol ML. A controlled trial of a program for the active management of labor. New Eng J Med. 1992; 326(7):450-454. doi: 10.1056/ NEJM 199202133260 705 .

12. Stephenson P. International Differences in the Use of Obstetrical Interventions. Copenhagen: World Health Organization Regional Office for Europe, 1992.

13. Fraser W. Early oxytocin to shorten spontaneous labor. In: Chalmers I, Enkin M, Keirse M (eds). Oxford Database of Perinatal Trials. Version 1.3, disk issue 8, Oxford University Press, Oxford 1992b.

14. O'Herlihy C. Active management: a continuing benefit in nulliparous labour. Birth. 1993;20(2):95-97. doi: https://doi.org/ 10.1111/j. 1523-536X.1993. tb00 424.x.

15. O'Driscoll K, Meagher D, Boylan P. Active management of labor. $3^{\text {rd }}$ ed. London: Mosby-Year book, 1993.

16. Leveno KJ, Cunningham FG, Pritchard JA. Cesarean section: an answer to the house of Horne. Am J Obstet Gynecol 1985;153(8):838-844.
17. Leveno KJ, Cunningham FG, Pritchard JA. Cesarean section: the house of Horne revisited. Am J Obstet Gynecol. 1989;160(1):78-79. doi: https://doi.org/ 10.1016/0002-9378(89)90090-2.

18. O'Driscoll K, Foley M, MacDonald D. Active management of labor as an alternative to cesarean section for dystocia. Obstet Gynecol. 1984;63(4):485490

19. Stewart P, Kennedy JH, Calder AA. Spontaneous labour: when should the membranes be ruptured? $\mathrm{Br} \mathrm{J}$ Obstet Gynaecol. 1982;89(1):39-43.

20. Barrett JF, Savage J, Phillips K, Lilford RJ. Randomized trial of amniotomy in labour versus the intention to leave membranes intact until the second stage. Br J Obstet Gynaecol. 1992;99(1):5-9.

21. Wetrich DW. Effect of amniotomy upon labor: a controlled study. Obstet Gynecol. 1970;35(5):800-806.

22. Franks P. A randomized trial of amniotomy in active labor. J Fam Pract 1990; 31(3):49-52.

23. Fraser WD, Sauve R, Parboosingh IJ, Fung T, Sokol R, Persaud D. A randomized controlled trial of early amniotomy. Br J Obstet Gynaecol. 1991;98(1):84-91.

24. Frigoletto FD Jr, Lieberman E, Lang JM, Cohen A, Barss V, Ringer $\mathrm{S}$, et al A clinical trial of active management of labour. New Eng J Med.1995; 333 (12):745-750. doi: 10.1056/nejm199509213331201.

\section{How to cite this article?}

Snehlata, Kumar A, Sawant V. Comparison of active management of labour versus traditional approach. Obgs Rev: $J$ Obstet Gynecol 2019;5(5):218-224.doi:10.17511/joog.2019.105.02. 